\title{
Mismatched single stranded antisense oligonucleotides can induce efficient dystrophin splice switching
}

\author{
Clayton T Fragall ${ }^{1}$, Abbie M Adams ${ }^{1}$, Russell D Johnsen ${ }^{1}$, Ryszard Kole ${ }^{2}$, Sue Fletcher ${ }^{1}$ and Steve D Wilton ${ }^{1 *}$
}

\begin{abstract}
Background: Antisense oligomer induced exon skipping aims to reduce the severity of Duchenne muscular dystrophy by redirecting splicing during pre-RNA processing such that the causative mutation is by-passed and a shorter but partially functional Becker muscular dystrophy-like dystrophin isoform is produced. Normal exons are generally targeted to restore the dystrophin reading frame however, an appreciable subset of dystrophin mutations are intra-exonic and therefore have the potential to compromise oligomer efficiency, necessitating personalised oligomer design for some patients. Although antisense oligomers are easily personalised, it remains unclear whether all patient polymorphisms within antisense oligomer target sequences will require the costly process of producing and validating patient specific compounds.
\end{abstract}

Methods: Here we report preclinical testing of a panel of splice switching antisense oligomers, designed to excise exon 25 from the dystrophin transcript, in normal and dystrophic patient cells. These patient cells harbour a single base insertion in exon 25 that lies within the target sequence of an oligomer shown to be effective at removing exon 25.

Results: It was anticipated that such a mutation would compromise oligomer binding and efficiency. However, we show that, despite the mismatch an oligomer, designed and optimised to excise exon 25 from the normal dystrophin mRNA, removes the mutated exon 25 more efficiently than the mutation-specific oligomer.

Conclusion: This raises the possibility that mismatched AOs could still be therapeutically applicable in some cases, negating the necessity to produce patient-specific compounds.

\section{Background}

Antisense oligomer (AO) induced exon skipping has emerged as a promising approach to reduce the severity of Duchenne Muscular Dystrophy (DMD), progressing rapidly from concept to the completion of several clinical trials [1-4]. This therapy uses AOs to modify splicing during pre-RNA processing, such that a DMD-associated exon is removed and a shorter but partially functional Becker muscular dystrophy (BMD)-like dystrophin isoform is produced. Most commonly, splice switching AOs are designed to target motifs in the normal dystrophin gene transcript, which is appropriate, since the most common type of DMD mutation is a deletion of one or

\footnotetext{
* Correspondence: swilton@cyllene.uwa.edu.au

${ }^{1}$ Centre for Neuromuscular and Neurological Disorders, University of Western Australia, 35 Stirling Highway, Crawley, Western Australia 6009, Australia Full list of author information is available at the end of the article
}

more exons and it is the normal exon, flanking the deletion that must be removed to restore the reading frame. In addition, it may be assumed that normal exons will generally be more difficult to dislodge than a mutated counter-part, since the full complement of splicing motifs will be present in the former.

Disease-causing gene lesions, silent polymorphisms or small intra-exonic deletions, insertions or substitutions may occur within the oligomer annealing region, or impact upon splice control motifs. These could potentially alter the efficacy of an AO designed and optimised for the normal dystrophin gene transcripts. Data from the Human Genome Project suggests that single nucleotide polymorphisms (SNPs) occur every 100-300 bases http://www.ornl.gov/sci/techresources/Human_Genome/ faq/snps.shtml. Although the distribution of these SNPs is non-random, their incidence means that patients may

\section{Biomed Central}

(c) 2011 Fragall et al; licensee BioMed Central Ltd. This is an Open Access article distributed under the terms of the Creative Commons Attribution License (http://creativecommons.org/licenses/by/2.0), which permits unrestricted use, distribution, and reproduction in any medium, provided the original work is properly cited. 
harbour a SNP in the target exon. Given that dystrophin exons are, on average, only $150 \mathrm{bp}$ long and splice switching AOs are designed as 25-32mers, patients carrying intra-exonic disease-causing mutations will have an approximately 1 in 6 chance that the gene lesion will occur within the $\mathrm{AO}$ annealing sequence. Consequently, even DMD boys with the "same" mutation at the mRNA level (e.g. a genomic deletion of exon 50) will almost certainly have unique dystrophin genes because of differences in disease-associated deletion break-points, as well as non-disease associated DNA variations in both protein-coding and non-coding regions. It should not be unexpected that each DMD boy could respond to induced exon skipping in a unique manner. For this reason, the development of optimal exon skipping strategies for most DMD mutations are best evaluated in cells from the patient.

Subtle dystrophin gene changes, such as intra-exonic insertion/deletions/substitutions collectively represent less than $30 \%$ of cases but are spread across the dystrophin gene, making them a lower priority for immediate clinical development than amenable mutation sub-types in the deletion hotspots. In anticipation of accelerated development of oligomer induced exon skipping as a therapy for DMD, we wish to develop effective exon skipping strategies for as many different DMD mutations as possible. As described by Wilton et al [5], we have optimised AOs to exclude each of the exons in the dystrophin transcript, excluding the first and last exons, and are now focused upon further refining AO design during pre-clinical testing in DMD patient cell lines.

Here we present the optimization of oligomers to skip exon 25, and report the unexpected finding that a mismatched oligomer induced efficient exon exclusion in cells from a young patient, with a single base insertion in exon 25 (c.3385 Insertion A) that lies within the optimized AO target sequence.

\section{Methods}

\section{AO design and synthesis}

Oligomers consisting of 2'-O-methyl (2OMe) modified bases on a phosphorothioate backbone were synthesized on an Expedite 8909 synthesizer (Applied Biosystems, Melbourne, Australia), as described by Adams et al. [6]. AO sequences are shown in Table 1 (AO nomenclature

\section{Table 1 Oligomer Sequences}

\begin{tabular}{cc}
\hline Oligomer & Sequence $\left(\mathbf{5}^{\prime}\right.$ to $\mathbf{3}^{\prime}$ ) \\
\hline$H 25 A(+10+33)$ & UGG GCU GAA UUG UCU GAA UAU CAC \\
H25A(+95+119) & UUG AGU UCU GUC UCA AGU CUC GAA G \\
H25A(+95+A+119) & UUG AGU UCU GUU CUC AAG UCU CGA AG \\
H25D(+16-08) & GUC UAU ACC UGU UGG CAC AUG UGA \\
H25D(+06-14) & GAG AUU GUC UAU ACC UGU UG \\
\hline
\end{tabular}

according to Mann et al [7]). The optimal sequence to excise exon 25 was then prepared and supplied by AVI Biopharma Inc (Bothell, WA) as a phosphorodiamidate morpholino oligomer (PMO) conjugated to a cell-penetrating peptide (PPMO- $k$ ) $[8,9]$.

\section{Cell Culture and Transfection}

Normal human myoblasts were prepared as described by Rando et al. [10] from de-identified muscle biopsies, obtained with informed consent during elective surgery in the Department of Neuropathology at Royal Perth Hospital. Similarly donated after informed consent, deidentified fibroblasts were obtained from a DMD patient harbouring a frame shifting mutation in exon 25 (c.3385 Insertion A). Fibroblasts were cultured in DMEM (Invitrogen, Melbourne, Australia) supplemented with 20\% foetal calf serum (FCS) (Serana, Bunbury, Australia), 1\% GlutaMax ${ }^{\mathrm{TM}}$-I (Gibco, Melbourne, Australia), $10 \mathrm{U} / \mathrm{ml}$ penicillin (Invitrogen), $10 \mathrm{mg} / \mathrm{ml}$ streptomycin (Invitrogen), and $250 \mathrm{ng} / \mathrm{ml}$ amphotericin B (Sigma, Sydney, Australia). Fibroblasts were converted to myoblasts through forced myogenesis by transfection with a MyoD expressing adenovirus [11] and then differentiated in low serum media. Briefly, patient fibroblasts were cultured to $80 \%$ confluency, washed with PBS, detached with $0.25 \%$ Trypsin (w/v) (Gibco), inactivated with media containing $10 \%$ FCS, pelleted by centrifugation at $600 \times \mathrm{g}$ and then resuspended in DMEM supplemented with $5 \%$ horse serum and the MyoD adenoviral vector at a multiplicity of infection of 250. Ninety six hours after treatment with the MyoD adenoviral vector the fibroblasts were transfected with AO. The use of human tissue was approved by the University of Western Australia Human Ethics Committee (approval number RA/ 4/1/2295).

Normal myoblasts were proliferated and differentiated as described previously by Harding et al. [12]. All cells were plated at $2 \times 10^{4}$ cells/well in 24 well plates that had been sequentially pre-treated for 1 hour with $50 \mu \mathrm{g} /$ $\mathrm{ml}$ poly D-lysine (Sigma) and $100 \mu \mathrm{g} / \mathrm{ml}$ Matrigel (BD Biosciences, Sydney, Australia).

2OMeAOs were transfected as lipoplexes with Lipofectamine $2000^{\circledR}(1: 1 \mathrm{w} / \mathrm{w})$ (Invitrogen) in Opti-MEM media (Gibco) as per the manufacturer's instructions. PPMO- $k$ solutions were warmed for 5 minutes at $37^{\circ} \mathrm{C}$ before being diluted in Opti-MEM media as indicated and applied directly to the adherent cells.

\section{RNA extraction and nested RT-PCR}

Total RNA was harvested $96 \mathrm{~h}$ after transfection from duplicate wells using TRIzol ${ }^{\circledR}$ (Invitrogen) according to the manufacturer's instructions, and resuspended in 30 $\mu \mathrm{l}$ of sterile water (Baxter Healthcare, Sydney, Australia). Approximately $100 \mathrm{ng}$ of total RNA was used as 
template for primary amplification using Superscript ${ }^{(B)}$ III One-step RT-PCR system with Platinum Taq (Invitrogen) to amplify exons 13 to 27. After 35 cycles (myoblasts) and 40 cycles (MyoD converted fibroblasts) a $1 \mu \mathrm{L}$ aliquot was removed and subjected to nested PCR to amplify exons 18 to 26 for 30 cycles (myoblasts) or 35 cycles (MyoD converted fibroblasts), using AmpliTaq Gold (Applied Biosystems). Details of PCR primers (Geneworks, Adelaide, Australia) are shown in Table 2.

\section{Gel Analysis, Imaging and Sequencing}

PCR products were resolved on $2 \%$ agarose gels in TAE buffer and relative exon skipping efficiency estimated by densitometry of the full length and AO induced PCR products on images captured by the Chemi-Smart 3000 system (Vilber Lourmat, Marne-la-Vallée, France) as described previously [6]. Where necessary, the identity of induced transcripts was confirmed by band stab isolation [13], purification of templates using UltraClean spin columns (MoBio, Carlsbad, CA) and DNA sequencing using BigDye V3.1 terminator chemistry (Applied Biosystems) as per manufacturer's instructions. Sequencing was conducted at the Lotterywest State Biomedical Facility Genomics (Perth, Australia).

\section{Western analysis of dystrophin expression}

Western blotting was performed using a protocol derived from Cooper et al [14] and Nicholson et al [15]. Cells were harvested by trypsinisation, 7 days after transfection and placed in treatment buffer $(100 \mu \mathrm{l} / 4.5$ mg wet pellet weight) consisting of $125 \mathrm{mM}$ Tris- $\mathrm{HCl}$ pH 6.8, 15\% SDS, 10\% glycerol, $0.5 \mathrm{mM}$ PMSF, $50 \mathrm{mM}$ dithiothreitol, bromophenol blue $(0.004 \% \mathrm{w} / \mathrm{v})$ and a protease inhibitor cocktail $(15 \mu \mathrm{l} / 500 \mu \mathrm{l}$ of treatment buffer) (Sigma). Samples were vortexed briefly, sonicated for 1 second, 4-8 times at a setting of 30/100 on an ultrasonic processor (Sonics, Newtown, CT) and heated at $95^{\circ} \mathrm{C}$ for 5 minutes. Samples were then electrophoresed at $16^{\circ} \mathrm{C}$ on a $3-10 \%$ Tris- Bis/Glycine SDS gradient gel at $\mathrm{pH} 8.8$ with a $3 \%$ stacking gel $\mathrm{pH}$ 6.8. Gel contents were electrophoretically transferred to a FluorotransW PVDF membrane (Pall, Melbourne, Australia) overnight at $18^{\circ} \mathrm{C}$ at $290 \mathrm{~mA}$ in a transfer buffer without methanol. Dystrophin was detected with NCL-DYS2

Table 2 Dystrophin primers used for nested RT-PCR

\begin{tabular}{cccc}
\hline PCR & Exon & Direction & Sequence $\left(\mathbf{5}^{\prime}\right.$ to $\mathbf{3}^{\prime}$ ) \\
\hline Primary & 13 & Forward & AGC TTC AAG AAG ATC TAG AAC AAG \\
& & & AAC A \\
Primary & 27 & Reverse & GCT ATG ACA CTA TाT ACA GAC TC \\
Secondary & 18 & Forward & GAT ATA ACT GAA GTT CAC AG \\
Secondary & 26 & Reverse & ATT CGT GCA TCT CTG ATA GAT C \\
\hline
\end{tabular}

monoclonal anti-dystrophin (Novocastra, Newcastleupon-Tyne, UK) applied at a dilution of 1:100 for 2 hours at room temperature. Detection was performed using a Western Breeze kit as per the manufacturer's instructions (Invitrogen). Enhanced Chemiluminescence reactions were detected directly by the Chemi-Smart 3000 gel documentation system (Vilber Lourmat), using Chemi-Capt software for image acquisition and Bio-1D software for image analysis.

\section{Results}

The splice motif predictor programs, ESE finder [16], and Rescue ESE [17] were used to predict putative exonic splicing enhancers (ESEs) in exon 25 (Figure 1). Annealing co-ordinates of AOs relative to the predictive ESE positions are indicated.

2OMeAOs designed to target the predicted splicing motifs in dystrophin exon 25 (Table 1 and Figure 1) were transfected into normal human myoblasts (Figure 2A). In normal cells, all AOs tested demonstrated robust skipping of exon 25 at $100 \mathrm{nM}$ and were effective at the lower concentration of $2.5 \mathrm{nM}$.

Figure $2 \mathrm{~B}$ shows the levels of exon 25 skipping in MyoD converted patient fibroblasts after treatment with the same panel of AOs. H25D(+16-08) and H25D (+0614), targeting the exon 25 donor splice site, did not induce the same degree of exon skipping efficiency in the patient cells (Figure 2B). H25A $(+10+33)$ induced similar levels of exon 25 excision in patient and normal cells, whereas $\mathrm{H} 25 \mathrm{~A}(+95+119)$ performed better in patient cells than in normal cells at all concentrations tested (Figure 2B and 2C).

$\mathrm{H} 25 \mathrm{~A}(+95+119)$ targets the region of dystrophin exon 25 that encompasses the causative mutation. Since this mismatched oligomer generated such effective exon skipping, we subsequently examined the patient's mutation by direct DNA sequencing and confirmed the original diagnosis of a single base insertion of an A, 110 bases from the beginning of exon 25 (Figure 3A). This mutation occurs 11 bases downstream from the 5 ' end of $\mathrm{H} 25 \mathrm{~A}(+95+119)$, raising questions about how it might be influencing AO efficacy (Figure $3 \mathrm{~B}$ and $3 \mathrm{C}$ ). To investigate this we then designed a mutation specific AO to target the same coordinates.

AO H25A(+95+A+119) was produced as a patientspecific $\mathrm{AO}$ with perfect complementarity when annealing to the patient dystrophin transcript (Figure 3D and Table 1). Surprisingly, transfection of patient cells with $\mathrm{H} 25 \mathrm{~A}(+95+\mathrm{A}+119)$ shows that perfect complementarity is not essential for efficient exon skipping in this case (Figure 4). Although the additional base makes little difference when compared to $\mathrm{H} 25 \mathrm{~A}(+95+119)$ in normal cells, despite the mismatch (Figure 4A), in the patient cells $\mathrm{H} 25 \mathrm{~A}(+95+\mathrm{A}+119)$ reduces the efficiency of exon 


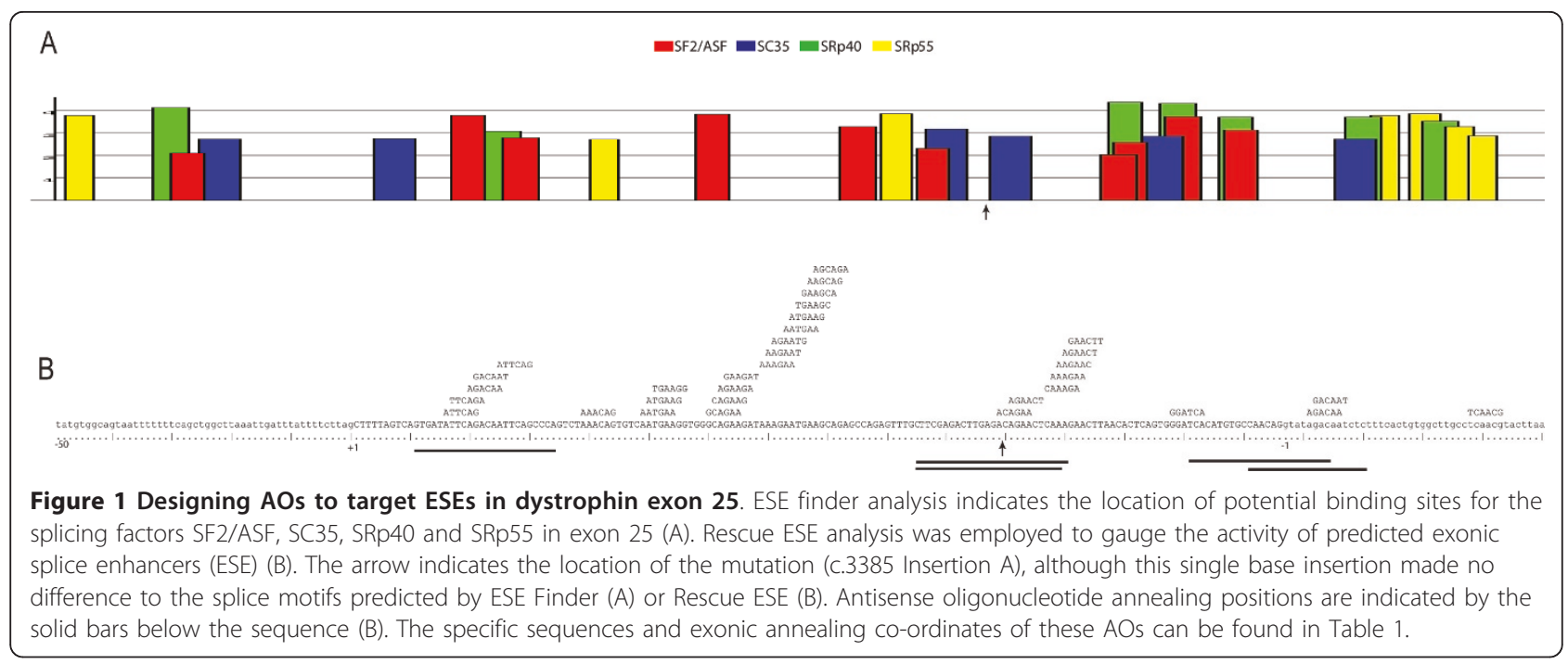

skipping, particularly evident at lower transfection concentrations (Figure 4B).

DMD patient fibroblasts were converted to myoblasts by forced myogenesis and transfected with $\mathrm{H} 25 \mathrm{~A}(+95$ +119 )- $k$ (i.e. PPMO- $k$ chemistry). Untreated Myo-D converted DMD fibroblasts, and normal myoblasts were used as negative and positive controls, respectively. Figure 5 shows that transfection with $\mathrm{H} 25 \mathrm{~A}(+95+119)-k$ at $800 \mathrm{nM}$ led to significant skipping of exon 25 from the dystrophin transcript (Figure 5A), and production of dystrophin protein (Figure 5B) whereas neither could be detected in patient forced myogenic cells. Sequencing of

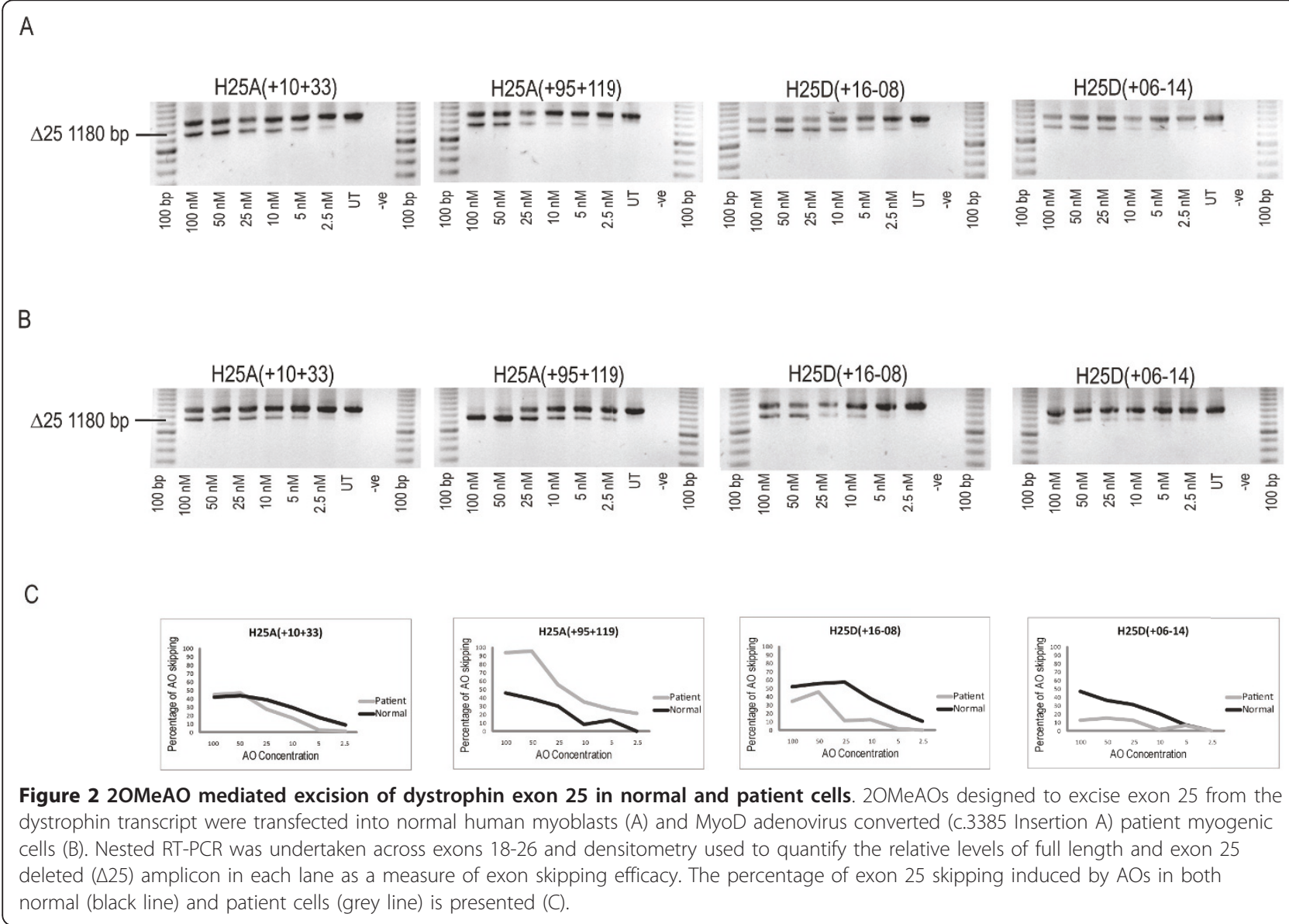


A

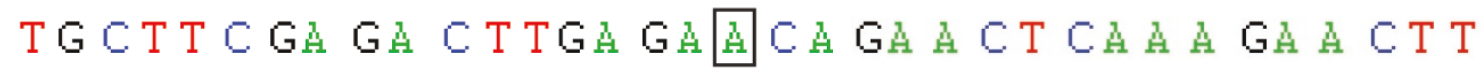
(n)

B $\mathrm{H} 25 \mathrm{~A}(+95+119)$

Normal mRNA

C $H 25 A(+95+119)$ Patient mRNA

D $H 25 A(+95+A+119)$ Patient mRNA

E $\mathrm{H} 25 \mathrm{~A}(+95+\mathrm{A}+119)$

Figure 3 Confirmation of the patient dystrophin mutation and the potential effect on AO Annealing. The dystrophin (c.3385 Insertion A) mutation was confirmed by direct sequencing (A). This mutation occurs within the annealing site of $\mathrm{H} 25 \mathrm{~A}(+95+119)$ suggesting a number of potential scenarios for the binding of $\mathrm{H} 25 \mathrm{~A}(+95+119)$ or $\mathrm{H} 25 \mathrm{~A}(+95+\mathrm{A}+119)$ including; perfect complementarity between $\mathrm{H} 25 \mathrm{~A}(+95+119)$ and normal dystrophin mRNA (B), a single base "bulge" in the mRNA when H25A(+95+119) binds to patient mRNA (C), perfect complementarity between $\mathrm{H} 25 \mathrm{~A}(+95+\mathrm{A}+119)$ and patient mRNA (D) and a single base "bulge" in $\mathrm{H} 25 \mathrm{~A}(+95+\mathrm{A}+119)$ when this oligomer binds to normal mRNA (E).

the predominant PCR products generated from the $\mathrm{H} 25 \mathrm{~A}(+95+119)-k$ treated patient and control myoblasts (Figure 5A) confirmed the exclusion of exon 25 from the amplicon (Figure 5C and 5D).

\section{Discussion}

DMD patients with whole exon deletions or duplications can potentially be treated by excising normal exons that should occur in a near-normal context. For this reason, unaffected normal human myoblasts are routinely used for the development and optimisation of splice-switching $\mathrm{AO}$ sequences, and we have previously shown that the AOs that are most effective in normal cells are generally also the most effective in patient cells [18]. However, we recently reported that some intra-exonic changes can influence the efficiency of AO-mediated splice manipulation [19].
A panel of AOs were designed to target human dystrophin exon 25 and when applied to patient cells carrying a single base insertion, all induced exon 25 excision. This DMD-causing gene lesion did not alter any exonic splicing motifs, as determined by in silico analysis, but most unexpectedly $\mathrm{H} 25 \mathrm{~A}(+95+119)$, which annealed across the insertion and was therefore mismatched, induced the most robust exon skipping. When compared to the profile of exon skipping induced in normal cells, H25A $(+95+119)$ appeared to be about twice as effective in the patient cells at all concentrations tested. Some enhancement of exon skipping in the patient cells would be due to the now in-frame, AO induced transcripts no longer being subjected to nonsense mediated decay (NMD). Evasion of NMD would increase the mRNA half life of the transcript missing exon 25, thereby increasing its 


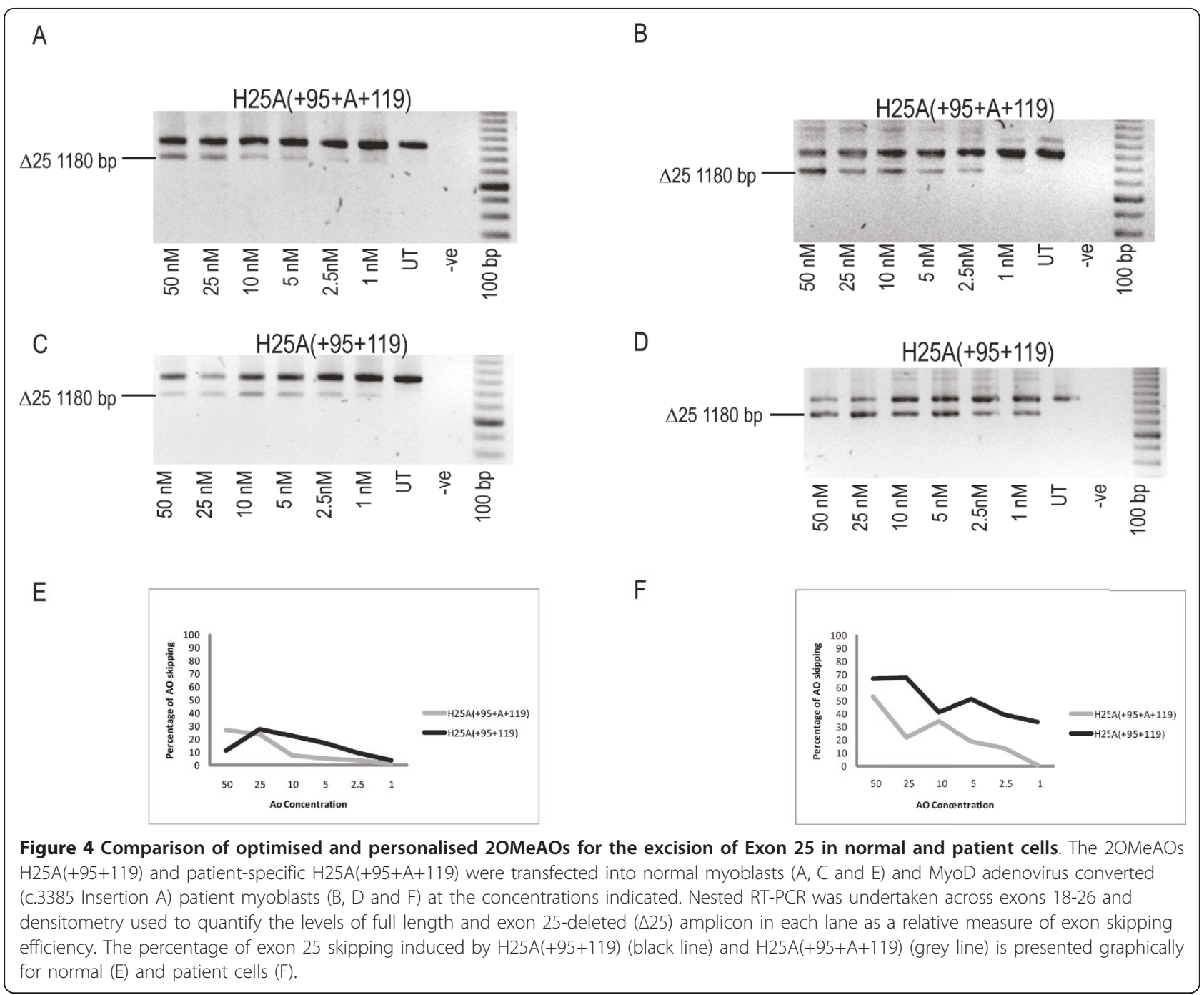

abundance in relation to the out-of-frame DMD transcript. Conversely, removal of exon 25 from the normal dystrophin gene transcript does not disrupt the reading frame, hence intact and exon 25-deleted transcripts should show similar turnover.

We can only speculate as to why the mismatched H25A $(+95+119)$ oligomer performed so effectively in the patient cells in comparison to the mutation specific $\mathrm{H} 25 \mathrm{~A}(+95+\mathrm{A}$ $+119)$. Previous mismatched oligomer studies by us [20] and others [21,22], utilized sequences with mismatched bases but no insertions or deletions within the oligomer: mRNA duplex. Here, we have an oligomer annealing across a single base insertion that would presumably loopout and/or alter the secondary structure of the pre-mRNA to further compromise exon recognition and selection. The exon 25 skipping induced by the patient-specific oligomer was comparable to that generated after transfection with the originally optimized $\mathrm{H} 25 \mathrm{~A}(+95+119)$ in normal cells. We are now re-evaluating oligomer design in our laboratory and including selected mismatches in well-studied splice switching oligomers to determine if this effect is unique to this mutation or reflects a more general mechanism (e.g. miRNA binding of seed sequences in their target gene transcripts [23]).

Testing of oligomers in patient cells will be the most appropriate way to determine if patient-specific mutations or polymorphisms compromise AO efficacy, and in the event of diminished oligomer efficacy, an alternative sequence should be evaluated. Data reported by us $[20]$ and others $[21,22]$ have reported that mismatched AOs compromise exon skipping efficiency and we predicted that personalizing an oligomer optimized in normal cells to match the patient sequence would further enhance efficacy. However, this proved otherwise in the case presented here. The personalized $\mathrm{H} 25 \mathrm{~A}(+95+\mathrm{A}$ +119 ) induced exon skipping in both normal and patient cells but at markedly lower levels than the mismatched oligomer designed to the normal dystrophin coordinates. 


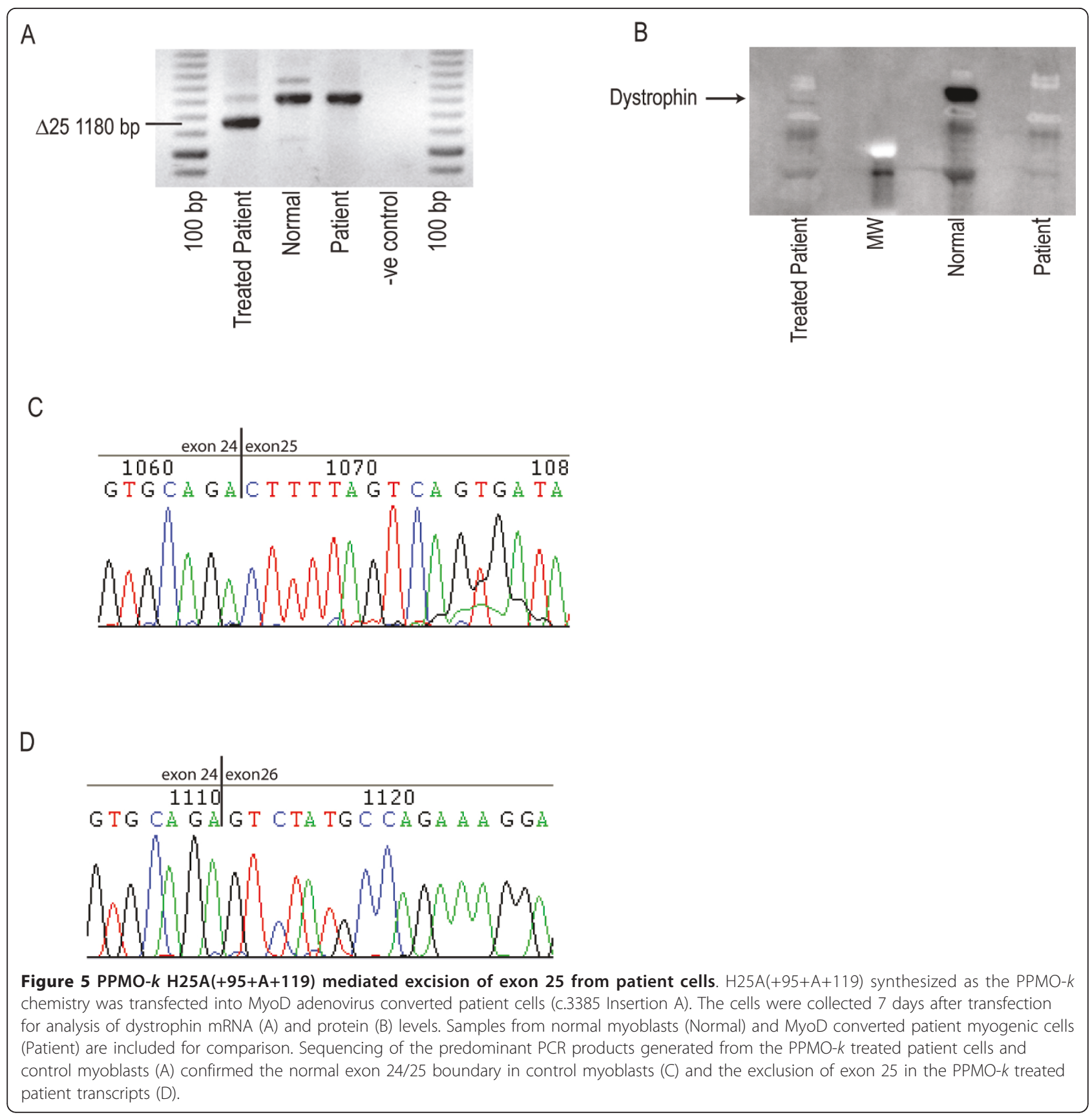

Detecting dystrophin protein following induced exon skipping in DMD fibroblasts that had undergone forced myogenesis with the MyoD adenovirus can be technically challenging, and we were unable to demonstrate dystrophin by Western blotting after treatment with the $2 \mathrm{OMe}$ $\mathrm{H} 25 \mathrm{~A}(+95+119)$. In order to confirm that the efficacy of the mismatched oligomer was not chemistry specific, forced myogenic DMD cells were transfected with the oligomer sequence prepared as PPMO- $k$. Efficient exon skipping and detectable dystrophin protein was induced after $\mathrm{H} 25 \mathrm{~A}(+95+119)-k$ treatment, indicating that this effect could also be achieved with the morpholino oligomer chemistry. We did not contemplate using a customized PPMO- $k$ for this mutation because of the cost of the compound and its restricted applicability.

\section{Conclusions}

Initially, exon skipping to treat DMD will only be applied to deletions within mutation hotspots. This is despite the fact that nearly half of the dystrophin exons are in-frame and therefore many intra-exonic mutations could be addressed by single exon skipping. Although many such 
exons will be highly amenable targets for oligomer intervention, the incentive to pursue these targets is limited by the fact that in-frame exons do not restore commonly encountered exon deletion frame-shifts and intra-exonic mutations are spread across the gene, with no prominent hotspots. Furthermore, the presence of intra-exonic mutations or SNPs may increase or decrease exon skipping efficacy by altering splice motifs or directly compromising oligomer annealing, implying that the patients may require mutation-specific oligomer design. Toxicology and safety validation adds significant costs to bringing each $\mathrm{AO}$ to the clinic, and even single base changes (e.g. personalisation) to approved AO designs will require such validation. Here we show that this level of personalised medicine may not be necessary in all cases.

\section{Acknowledgements}

This work was supported by funding from the National Institutes of Health (5R01NS044146-06), the Muscular Dystrophy Association USA (1734027), Duchenne Ireland, the Killowen Fundraising Group, the Muscular Dystrophy Association WA Inc., and the Medical and Health Research Infrastructure Fund of Western Australia. We wish to acknowledge assistance of Dr Christopher Barnett, Clinical Geneticist at the Women's \& Children's Hospital, Adelaide, South Australia.

\section{Author details}

${ }^{1}$ Centre for Neuromuscular and Neurological Disorders, University of Western Australia, 35 Stirling Highway, Crawley, Western Australia 6009, Australia. ${ }^{2}$ AVI Biopharma, 3450 Monte Villa Parkway, Bothell, WA 98021, USA.

\section{Authors' contributions}

CTF participated in data analysis and interpretation, and drafted the manuscript. AMA and RDJ were responsible for data acquisition and analysis. SF, RK and SDW conceived of the study and participated in its design, coordination and interpretation. All authors reviewed the draft documents and approved the final manuscript.

\section{Competing interests}

The authors declare that they have no competing interests.

Received: 4 July 2011 Accepted: 20 October 2011

Published: 20 October 2011

\section{References}

1. van Deutekom JC, Janson AA, Ginjaar IB, Frankhuizen WS, Aartsma-Rus A, Bremmer-Bout M, den Dunnen JT, Koop K, van der Kooi AJ, Goemans NM, et al: Local dystrophin restoration with antisense oligonucleotide PRO051. N Engl J Med 2007, 357:2677-2686.

2. Kinali M, Arechavala-Gomeza V, Feng L, Cirak S, Hunt D, Adkin C, Guglieri M, Ashton E, Abbs S, Nihoyannopoulos $P$, et al: Local restoration of dystrophin expression with the morpholino oligomer AVI-4658 in Duchenne muscular dystrophy: a single-blind, placebo-controlled, doseescalation, proof-of-concept study. Lancet Neurol 2009, 8:918-928.

3. Goemans NM, Tulinius M, van den Akker JT, Burm BE, Ekhart PF, Heuvelmans N, Holling T, Janson AA, Platenburg GJ, Sipkens JA, et al: Systemic Administration of PRO051 in Duchenne's Muscular Dystrophy. N Engl J Med 2011.

4. Cirak S, Arechavala-Gomeza V, Guglieri M, Feng L, Torelli S, Anthony K, Abbs S, Garralda ME, Bourke J, Wells DJ, et al: Exon skipping and dystrophin restoration in Duchenne Muscular Dystrophy patients after systemic phosphorodiamidate morpholino oligomer treatment. Lancet .

5. Wilton SD, Fall AM, Harding PL, McClorey G, Coleman C, Fletcher S: Antisense oligonucleotide-induced exon skipping across the human dystrophin gene transcript. Mol Ther 2007, 15:1288-1296.
6. Adams AM, Harding PL, Iversen PL, Coleman C, Fletcher S, Wilton SD: Antisense oligonucleotide induced exon skipping and the dystrophin gene transcript: cocktails and chemistries. BMC Mol Biol 2007, 8:57.

7. Mann CJ, Honeyman K, McClorey G, Fletcher S, Wilton SD: Improved antisense oligonucleotide induced exon skipping in the $\mathrm{mdx}$ mouse model of muscular dystrophy. J Gene Med 2002, 4:644-654.

8. Jearawiriyapaisarn N, Moulton HM, Buckley B, Roberts J, Sazani P, Fucharoen S, Iversen PL, Kole R: Sustained dystrophin expression induced by peptide-conjugated morpholino oligomers in the muscles of $\mathrm{mdx}$ mice. Mol Ther 2008, 16:1624-1629.

9. Moulton HM, Fletcher S, Neuman BW, McClorey G, Stein DA, Abes S, Wilton SD, Buchmeier MJ, Lebleu B, Iversen PL: Cell-penetrating peptidemorpholino conjugates alter pre-mRNA splicing of DMD (Duchenne muscular dystrophy) and inhibit murine coronavirus replication in vivo. Biochem Soc Trans 2007, 35:826-828.

10. Rando TA, Blau HM: Primary mouse myoblast purification, characterization, and transplantation for cell-mediated gene therapy. J Cell Biol 1994, 125:1275-1287.

11. Lattanzi L, Salvatori G, Coletta M, Sonnino C, Cusella De Angelis MG, Gioglio L, Murry CE, Kelly R, Ferrari G, Molinaro M, et al: High efficiency myogenic conversion of human fibroblasts by adenoviral vectormediated MyoD gene transfer. An alternative strategy for ex vivo gene therapy of primary myopathies. J Clin Invest 1998, 101:2119-2128.

12. Harding PL, Fall AM, Honeyman K, Fletcher S, Wilton SD: The influence of antisense oligonucleotide length on dystrophin exon skipping. Mol Ther 2006, 15:157-166.

13. Wilton SD, Lim L, Dye D, Laing N: Bandstab: a PCR-based alternative to cloning PCR products. Biotechniques 1997, 22:642-645.

14. Cooper ST, Lo HP, North KN: Single section Western blot: improving the molecular diagnosis of the muscular dystrophies. Neurology 2003, 61:93-97.

15. Nicholson LV, Davison K, Falkous G, Harwood C, O'Donnell E, Slater CR, Harris JB: Dystrophin in skeletal muscle. I. Western blot analysis using a monoclonal antibody. J Neurol Sci 1989, 94:125-136.

16. Cartegni L, Wang J, Zhu Z, Zhang MQ, Krainer AR: ESEfinder: A web resource to identify exonic splicing enhancers. Nucleic Acids Res 2003, 31:3568-3571.

17. Fairbrother WG, Yeo GW, Yeh R, Goldstein P, Mawson M, Sharp PA, Burge CB: RESCUE-ESE identifies candidate exonic splicing enhancers in vertebrate exons. Nucleic Acids Res 2004, 32:W187-190.

18. Harding PL, Fall AM, Honeyman K, Fletcher S, Wilton SD: The influence of antisense oligonucleotide length on dystrophin exon skipping. Mol Ther 2007, 15:157-166.

19. Forrest S, Meloni PL, Muntoni F, Kim J, Fletcher S, Wilton SD: Personalized exon skipping strategies to address clustered non-deletion dystrophin mutations. Neuromuscul Disord 2010, 20:810-816.

20. Errington SJ, Mann CJ, Fletcher S, Wilton SD: Target selection for antisense oligonucleotide induced exon skipping in the dystrophin gene. J Gene Med 2003, 5:518-527.

21. Aartsma-Rus A, Kaman WE, Bremmer-Bout M, Janson AA, den Dunnen JT, van Ommen GJ, van Deutekom JC: Comparative analysis of antisense oligonucleotide analogs for targeted DMD exon 46 skipping in muscle cells. Gene Ther 2004, 11:1391-1398.

22. Heemskerk HA, de Winter CL, de Kimpe SJ, van Kuik-Romeijn P, Heuvelmans N, Platenburg GJ, van Ommen GJ, van Deutekom JC, AartsmaRus A: In vivo comparison of 2'-O-methyl phosphorothioate and morpholino antisense oligonucleotides for Duchenne muscular dystrophy exon skipping. J Gene Med 2009, 11:257-266.

23. Filipowicz W, Bhattacharyya SN, Sonenberg N: Mechanisms of posttranscriptional regulation by microRNAs: are the answers in sight? Nat Rev Genet 2008, 9:102-114.

Pre-publication history

The pre-publication history for this paper can be accessed here: http://www.biomedcentral.com/1471-2350/12/141/prepub

doi:10.1186/1471-2350-12-141

Cite this article as: Fragall et al:: Mismatched single stranded antisense oligonucleotides can induce efficient dystrophin splice switching. BMC Medical Genetics 2011 12:141. 